\title{
Potent Antiproliferative Effect on Liver Cancer of Medicinal Plants Selected from the Thai/Lanna Medicinal Plant Recipe Database "MANOSROI III"
}

\author{
Aranya Manosroi, ${ }^{1,2}$ Hiroyuki Akazawa, ${ }^{1,3}$ Worapong Kitdamrongtham,, \\ Toshihiro Akihisa, ${ }^{4,5}$ Worapaka Manosroi, ${ }^{2,6}$ and Jiradej Manosroi ${ }^{1,2}$ \\ ${ }^{1}$ Faculty of Pharmacy, Chiang Mai University, Chiang Mai 50200, Thailand \\ ${ }^{2}$ Manose Health and Beauty Research Center, Chiang Mai 50200, Thailand \\ ${ }^{3}$ Department of Biotechnology and Material Chemistry, Nihon University Junior College, Chiba 274-8501, Japan \\ ${ }^{4}$ College of Science and Technology, Nihon University, Tokyo 101-8308, Japan \\ ${ }^{5}$ Akihisa Medical Clinic, 1086-3 Kamo, Sanda-shi, Hyogo 669-1331, Japan \\ ${ }^{6}$ Faculty of Medicine, Chiang Mai University, Chiang Mai 50200, Thailand
}

Correspondence should be addressed to Jiradej Manosroi; jiradej.manosroi8@gmail.com

Received 31 March 2015; Accepted 25 May 2015

Academic Editor: Shuang-En Chuang

Copyright (C) 2015 Aranya Manosroi et al. This is an open access article distributed under the Creative Commons Attribution License, which permits unrestricted use, distribution, and reproduction in any medium, provided the original work is properly cited.

Thai/Lanna medicinal plant recipes have been used for the treatment of several diseases including liver cancer. In this study, methanolic extracts (MEs) of 23 plants were tested for antiproliferative activity on human hepatoma cell line (Hep G2) by the sulforhodamine B (SRB) assay. Nine MEs with potent antiproliferative activity $\left(\mathrm{IC}_{50}<100 \mu \mathrm{g} / \mathrm{mL}\right)$ were obtained and further semipurified by liquid/liquid partition extraction. The semipurified fractions were tested for the antiproliferative and antioxidative activities. ME of Stemona collinsae and the semipurified extract and methanol-water fraction (MF) of Gloriosa superba gave the highest antiproliferative activity on HepG2 which were 4.79- and 50.07-fold cisplatin, respectively. The semipurified fractions showed an increased antiproliferative activity. MF of Caesalpinia sappan and HF of Senna alata showed the highest free radical scavenging and metal chelating activities, respectively. The compound in $n$-hexane fraction (HF) of Ventilago denticulata which showed an increase in antiproliferative activity comparing to its ME was isolated and identified as emodin. This study has demonstrated the potential of the ME from S. collinsae, MF from G. superba, and emodin isolated from $V$. denticulata, for further development as an antiliver cancer agent.

\section{Introduction}

Hepatocellular cancer and intrahepatic cholangiocarcinoma are the two major forms of primary liver cancers. The incidence of these two carcinomas is the fifth most common widespread cancer in the world. Hepatocellular carcinoma can damage the hepatic cells via oxidative stress and generation of inflammation related to hepatocarcinogenesis [1]. Several types of chemotherapeutic drugs have been used to treat hepatic cancer such as cisplatin, 5-fluorouracil, and paclitaxel. However, these drugs usually have some problems of cancer resistance, due to multidrug resistance protein and the decrease of apoptotic proteins. Recently, many medicinal plants have been investigated as an alternative of chemotherapeutic drugs. Most medicinal plants from traditional medicines are safer than the chemical substances with effectiveness. This may be due to the traditional uses in human for several generations. Only those which showed therapeutic efficacy and safety will be recorded and used until now.

The Lanna region covered several provinces in China, Laos, Myanmar, and Thailand. The Lanna region in Thailand includes seven provinces which are Chiang Mai, Chiang Rai, Lamphun, Lampang, Phayao, Phrae, and Nan. Lanna has its 
own folklore wisdom including traditional medicinal plant recipes. These recipes have been recorded and used for over 700 years. Interestingly, some of the recipes are still currently used in the northern part of Thailand for the treatment of several diseases such as fever, diarrhea, diabetes, tuberculosis, arthritis, and cancer. Professor Dr. Jiradej Manosroi from the Manose Research Center has collected the medicinal plant recipes from several institutions, temples, and folklore doctors in the Lanna area and other regions all over Thailand and put into the database called "MANOSROI III." Presently, this database contains about 200,000 medicinal plant recipes covering all diseases including cosmetics and food supplements $[2,3]$.

Anticancer activities of many Thai medicinal plants can be selected from the recipes in the "MANOSROI III" database. Some plants have shown potent antiproliferative activities via apoptotic action [3]. In this study, the antiproliferative activity on human hepatoma cell line (HepG2) and antioxidative activities of the methanol extracts of 23 plants selected from the Thai medicinal recipes database "MANOSROI III" were investigated. The extracts with strong antiproliferative activity were selected, further purified by liquid-liquid partition extraction, and reinvestigated and the potential to develop as anticancer compounds was anticipated.

\section{Materials and Methods}

2.1. Materials and Chemicals. Twenty-three plants with high frequency in the anticancer recipes were selected from the anticancer recipes in the Thai/Lanna medicinal recipe database "MANOSROI III." Searching of the anticancer recipes was performed by using Thai keywords which were Ma-reng and San which mean cancer. The plants were collected from Chiang Mai, Thailand during March to May 2010. The voucher specimens of the plants were authenticated by a botanist and deposited at NPRDC, Faculty of Pharmacy, Chiang Mai University in Chiang Mai, Thailand (Table 1). Methanol was obtained from Labscan Asia Co. Ltd. (Thailand). Fetal bovine serum (FBS) was from Gibco BRL (Ontario, Canada). Dulbecco's Modified Eagle Medium (DMEM) cell culture medium, dimethylsulfoxide (DMSO), sulforhodamine B (SRB), L-(+)-ascorbic acid, $\alpha$-tocopherol, 1,1-diphenyl-2-picrylhydrazyl (DPPH), ethylenediaminetetraacetic acid (EDTA), ferrozine, ferrous chloride $\left(\mathrm{FeCl}_{2}\right)$, Folin-Ciocalteu reagent, aluminium chloride $\left(\mathrm{AlCl}_{3}\right)$, potassium acetate $\left(\mathrm{CH}_{3} \mathrm{CO}_{2} \mathrm{~K}\right)$, and quercetin were purchased from Sigma Chemical Co. (St. Louis, MO, USA). Cisplatin and doxorubicin hydrochloride (doxorubicin) were from Dabur Pharma Ltd. (Hampshire, UK).

2.2. Crude Plant Extract Preparation. Ten grams of the dried and powdered plants was extracted with $200 \mathrm{~mL}$ of methanol ( $2 \mathrm{~h}$ reflux, 3 times). The mixture was filtered and the methanol filtrate was evaporated under reduced pressure using a rotary evaporator (Buchi, Switzerland) to give the methanol extract (ME). The yield was represented as percentages of the crude extracts comparing to the dried plant.

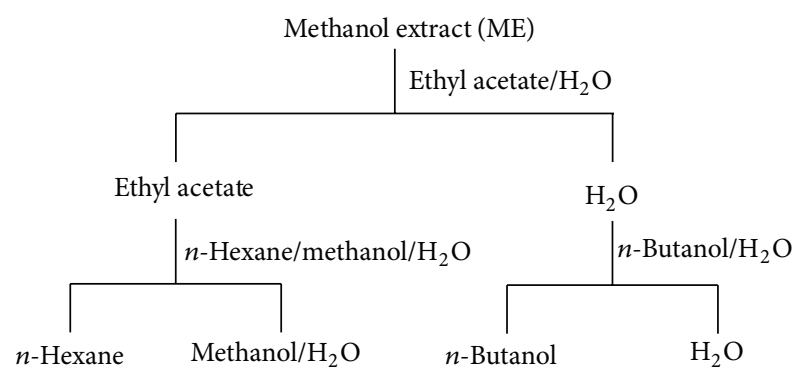

Figure 1: Liquid-liquid partition method from the methanolic extract (ME) to the 4 fractions ( $n$-hexane, methanol-water, $n$ butanol, and water soluble fractions).

2.3. Liquid-Liquid Partition Extraction. The $9 \mathrm{MEs}$ which gave the $\mathrm{GI}_{50}$ values of less than $100 \mu \mathrm{g} / \mathrm{mL}$ [active (A)/moderately active (MA) according to the NCI criteria] were selected and further fractionated by liquid-liquid partition extraction. Briefly, one gram of the MEs was dissolved in $100 \mathrm{~mL}$ of water and partitioned with an equal volume of ethyl acetate. The aqueous layer was reextracted with an equal volume of ethyl acetate for 2 times. The ethyl acetate layer was pooled, concentrated to $5 \mathrm{~mL}$, dissolved in $95 \mathrm{~mL}$ of methanol, and reextracted with $100 \mathrm{~mL}$ of hexane for 3 times to obtain the hexane (HF) and methanol-water (MF) soluble fractions. The aqueous layer was reextracted with an equal volume of $n$-butanol for 3 times to obtain $n$-butanol (BF) and water (WF) soluble fractions (Figure 1).

2.4. Compound Isolation from Ventilago denticulata. The dried stem of $V$. denticulata $(1.6 \mathrm{~kg})$ was extracted by methanol to obtain ME (100 g). A portion of ME (78 g) was extracted by liquid-liquid partition extraction to yield $\mathrm{HF}$ (15 g), MF (14 g), BF (17 g), and WF (16 g). According to the antiproliferative activity results, HF $(2.6 \mathrm{~g})$ was further fractionated by silica gel column chromatography (50 g) using the mixture of hexane and ethyl acetate as the mobile phase. Seven fractions (HF-1 7) according to the successive polarity range solvents (hexane/ethyl acetate $=1: 0$ to $0: 1$ ) were obtained. Fraction HF-2 (1.3 g) which was eluted by $90 \%$ hexane in ethyl acetate was further purified by silica gel column chromatography (50 g) using hexane-ethyl acetate to obtain the orange fraction (HF-2-O, hexane/ethyl acetate = $95: 5)$. This fraction was purified by the preparative HPLC with C18 column $(10 \phi \times 250 \mathrm{~mm}, 5 \mu)$ using methanol/water $=9: 1$ and the flow rate at $2.0 \mathrm{~mL} / \mathrm{min}$ to obtain a single compound.

\subsection{Antiproliferative Activity}

2.5.1. Sample Preparation. The MEs and fractions were dissolved in DMEM medium containing $0.5 \% \mathrm{v} / \mathrm{v}$ of DMSO [4] and DMSO, respectively. The samples were centrifuged at $5,000 \mathrm{~g}$, room temperature $\left(25 \pm 2^{\circ} \mathrm{C}\right)$ for $5 \mathrm{~min}$, sterilized by filtering through $0.2 \mu \mathrm{m}$ cellulose acetate membranes (Sartorius, Göttingen, Germany), and stored at $-20^{\circ} \mathrm{C}$. 
The final concentrations of MEs and fractions were in the range of $1 \times 10^{1}-1 \times 10^{-5}$ and $1-1 \times 10^{-6} \mathrm{mg} / \mathrm{mL}$, respectively.

2.5.2. Human Hepatic Cancer Cell Culture. The human hepatoma (Hep G2) cell line was obtained from Faculty of Tropical Medicine, Mahidol University, Bangkok, Thailand. The cells were subcultured into a $25 \mathrm{~cm}^{2}$ plastic flask containing DMEM supplemented with $10 \%$ of FBS, $100 \mathrm{U} / \mathrm{mL}$ of penicillin, and $100 \mathrm{mg} / \mathrm{mL}$ of streptomycin. The flask was incubated at $37^{\circ} \mathrm{C}$ in a humidified air incubator containing $5 \%$ carbon dioxide $\left(\mathrm{CO}_{2}\right)$.

2.5.3. Antiproliferative Activity by the Sulforhodamine B (SRB) Assay. Effects of extracts on the growth of Hep G2 cell line were evaluated according to the procedure of the American National Cancer Institute (NCI) for the in vitro anticancer drug screening using the protein-binding dye SRB to assess cell growth [5]. The assay was performed as previously described by Manosroi et al. [6] with some modifications. Briefly, cells were harvested, seeded into 96well plate (Gibthai Co. Ltd. Thailand) at the density of $1 \times$ $10^{4}$ cells/well, and incubated for $24 \mathrm{~h}$ at $37^{\circ} \mathrm{C}$ in a $5 \% \mathrm{CO}_{2}$ incubator. The cells were treated with various concentrations $\left(10-10^{-6} \mathrm{mg} / \mathrm{mL}\right)$ of the samples for 24 hours. After incubation, the cells were fixed with 50\% trichloroacetic acid and dyed with SRB solution. One hundred $\mu \mathrm{L}$ of Tris-solution was added to each well and incubated for $30 \mathrm{~min}$. The absorbance was measured at $540 \mathrm{~nm}$ by a microplate reader (Bio-Rad, model 680, Philadelphia, PA, USA). The final concentration of DMSO in each well was less than $1 \% \mathrm{v} / \mathrm{v}$ and the assays were done in triplicate. The percentage of growth inhibition $(\% G)$ was calculated as $\% G=\left(T_{\text {treat }}-T_{0}\right) /\left(T_{\text {control }}-T_{0}\right) \times 100$, where $T_{\text {treat }}$ was the absorbance of the samples after incubation for $24 \mathrm{~h}, T_{0}$ was the absorbance at initial $(0 \mathrm{~h})$, and $T_{\text {control }}$ was the absorbance of the control (DMSO only) after incubation for $24 \mathrm{~h}$. The dose response curve was prepared by plotting the $\% G$ versus the concentrations of the samples and the $\mathrm{IC}_{50}$ values (the concentrations of the samples giving $50 \%$ growth inhibition) were determined. Cisplatin and doxorubicin, the standard anticancer drugs, were used as the positive controls. Folds of activity in comparing with the standard drugs were calculated as follows: Folds $=\left(\mathrm{IC}_{50}\right.$ values of the standard drugs $) /\left(\mathrm{IC}_{50}\right.$ values of the samples).

\subsection{Antioxidative Activities}

2.6.1. 1,1-Diphenyl-2-Picrylhydrazyl (DPPH) Radical Scavenging Activity. The DPPH radical scavenging activity was determined by the method previously described [7]. Briefly, $50 \mu \mathrm{L}$ of the samples was put into 96-well microplate (Nalge Nunc International, NY, USA) and $50 \mu \mathrm{L}$ of ethanol solution of DPPH were added into each well and mixed. After incubation for $30 \mathrm{~min}$ at room temperature $\left(25 \pm 2^{\circ} \mathrm{C}\right)$, the absorbance was measured at $515 \mathrm{~nm}$ by a well plate reader (Bio-Rad, model 680 microplate reader, PA, USA) against the blank (DMSO). All samples were dissolved in DMSO and the final concentrations were adjusted to the range of $0.01-100 \mu \mathrm{g} / \mathrm{mL}$. Ascorbic acid and $\alpha$-tocopherol were used as the positive controls. The experiments were done in triplicate. $\mathrm{The}^{\mathrm{S}} \mathrm{C}_{50}$ value, the concentration of the sample that scavenged $50 \%$ of DPPH radical, was determined from the plotted curve.

2.6.2. Metal Chelating Activity. The metal chelating activity was determined by the ferrous iron-ferrozine complex method as previously described [7]. The mixture of the sample $(50 \mu \mathrm{L})$ and water $(20 \mu \mathrm{L})$ was added into a 96-well plate and $1.5 \mathrm{mM} \mathrm{FeCl}_{2}(10 \mu \mathrm{L})$ in water was added into each well and mixed. After incubation for $15 \mathrm{~min}$ at room temperature $\left(25 \pm 2^{\circ} \mathrm{C}\right)$ in darkness, $20 \mu \mathrm{L}$ of $3 \mathrm{mM}$ ferrozine in water was added into each well and the absorbance was measured by a microplate reader at $570 \mathrm{~nm}$ using DMSO as a negative control. The final concentration of the samples was varied within the range of $0.005-500 \mu \mathrm{g} / \mathrm{mL}$. EDTA was used as a positive control and the experiments were done in triplicate. The concentration in which the sample exhibited $50 \%$ metal chelating activity of ferrous ion $\left(\mathrm{CC}_{50}\right)$ was determined.

2.6.3. Total Phenolic Contents. The total phenolic contents as quercetin equivalents of the extracts and fractions were determined using the Folin-Ciocalteu reagent [7]. Briefly, $10 \mathrm{mg} / \mathrm{mL}$ of the samples was mixed with Folin-Ciocalteu reagent and $20 \%(\mathrm{w} / \mathrm{v})$ of sodium carbonate $\left(\mathrm{Na}_{2} \mathrm{CO}_{3}\right)$ at room temperature $\left(25 \pm 2^{\circ} \mathrm{C}\right)$. After incubation for $60 \mathrm{~min}$, the absorbance at $760 \mathrm{~nm}$ was measured by a microplate reader. The total phenolic contents of the samples were expressed as $\mu \mathrm{g}$ of quercetin equivalents (QE) per mg of the samples.

2.6.4. Total Flavonoid Contents. Aluminium chloride $\left(\mathrm{AlCl}_{3}\right)$ colorimetric method was used to determine the flavonoid contents with slight modification [8]. Briefly, $10 \mathrm{mg} / \mathrm{mL}$ of the samples was mixed with methanol, $5 \mu \mathrm{L}$ of $10 \% \mathrm{AlCl}_{3}, 5 \mu \mathrm{L}$ of $1 \mathrm{M} \mathrm{CH}_{3} \mathrm{CO}_{2} \mathrm{~K}$, and $140 \mu \mathrm{L}$ of distilled water and the mixture was adjusted to $250 \mu \mathrm{L}$ with methanol. After incubation at room temperature $\left(25 \pm 2^{\circ} \mathrm{C}\right)$ for $30 \mathrm{~min}$, the absorbance at $415 \mathrm{~nm}$ was measured with a microplate reader. The total flavonoid contents of the samples were expressed as $\mu \mathrm{g}$ of quercetin equivalents $(\mathrm{QE})$ per $\mathrm{mg}$ of the samples.

2.7. Statistical Analysis. All assays were performed in triplicate of three independent and separate experiments. The means of each test were calculated.

\section{Results}

3.1. Antiproliferative Activity of the 23 Methanolic Plant Extracts. Botanical names, families, parts used, yields, and antiproliferative activity on Hep G2 cell line of the 23 Thai medicinal plant MEs were shown in Table 1. According to the cytotoxicity activity criteria as established by the NCI, the $\mathrm{IC}_{50}$ values lower than $20 \mu \mathrm{g} / \mathrm{mL}$, in the range of 20 to $100 \mu \mathrm{g} / \mathrm{mL}$, and more than $100 \mu \mathrm{g} / \mathrm{mL}$ are regarded as active (A), moderately active (MA), and inactive (IA), respectively [9]. Only ME of S. collinsae showed A activity with the highest antiproliferative activities $\left(\mathrm{IC}_{50}=5.51 \mu \mathrm{g} / \mathrm{mL}\right)$ on HepG2 cell line which was 4.79 - and 0.10 -fold cisplatin and doxorubicin, 


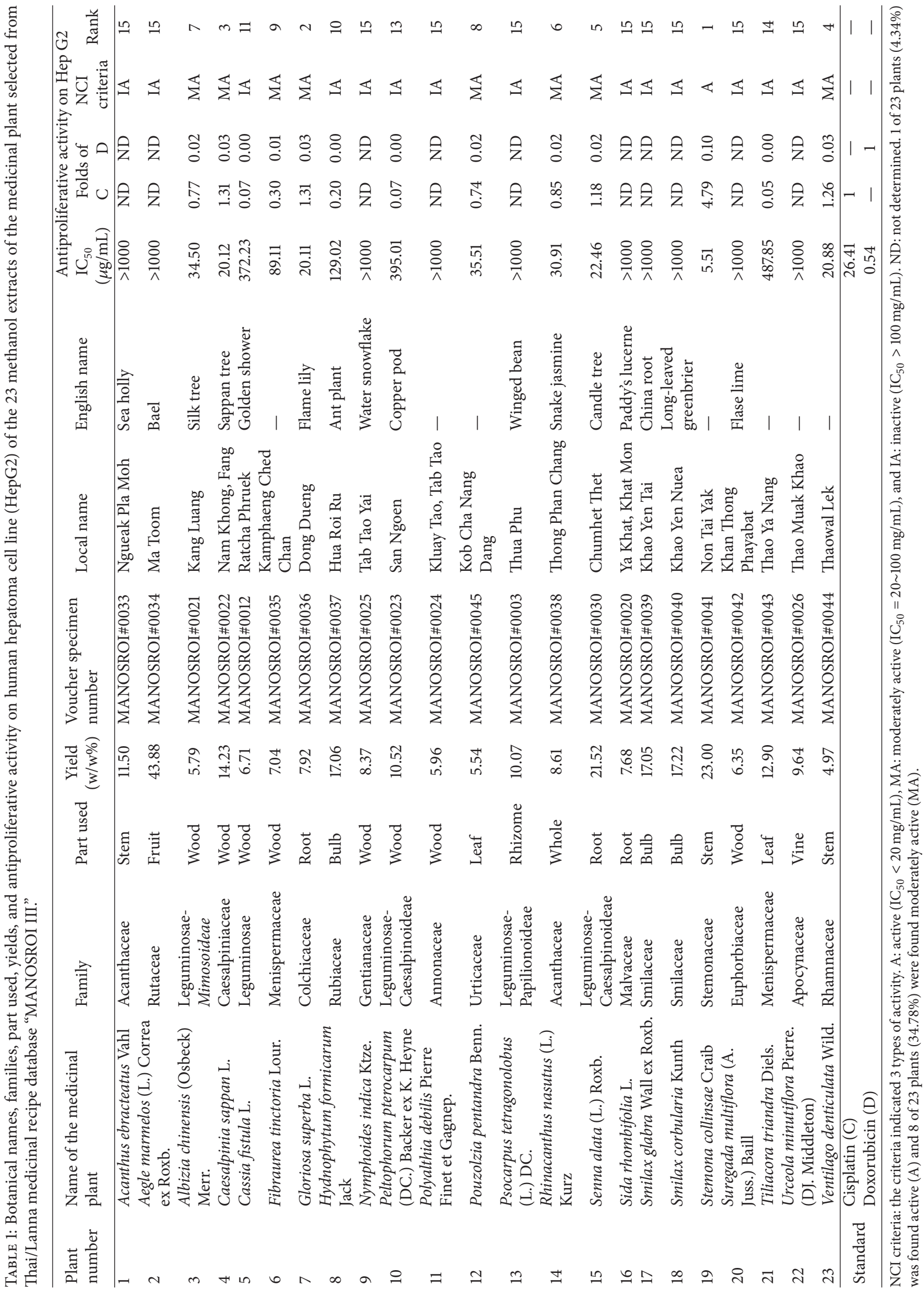


respectively. Eight MEs of G. superba $\left(\mathrm{IC}_{50}=20.11 \mu \mathrm{g} / \mathrm{mL}\right)$, C. $\operatorname{sappan}\left(\mathrm{IC}_{50}=20.12 \mu \mathrm{g} / \mathrm{mL}\right), V$. denticulata $\left(\mathrm{IC}_{50}=\right.$ $20.88 \mu \mathrm{g} / \mathrm{mL})$, S. alata $\left(\mathrm{IC}_{50}=22.46 \mu \mathrm{g} / \mathrm{mL}\right)$, Rhinacanthus nasutus $\left(\mathrm{IC}_{50}=30.91 \mu \mathrm{g} / \mathrm{mL}\right)$, Albizia chinensis $\left(\mathrm{IC}_{50}=\right.$ $34.50 \mu \mathrm{g} / \mathrm{mL})$, Pouzolzia pentandra $\left(\mathrm{IC}_{50}=35.51 \mu \mathrm{g} / \mathrm{mL}\right)$, and Fibraurea tinctoria $\left(\mathrm{IC}_{50}=89.11 \mu \mathrm{g} / \mathrm{mL}\right)$ which gave the $\mathrm{IC}_{50}$ values of less than $100 \mu \mathrm{g} / \mathrm{mL}$ were regarded as MA. The A and MA MEs and their fractions were further fractionated, tested for antiproliferative activity of these $9 \mathrm{MEs}$, and summarized in Table 2. The G. superba MF extract exhibited the highest antiproliferative activity with the $\mathrm{IC}_{50}$ value of $0.53 \mu \mathrm{g} / \mathrm{mL}$ (A) which was 37.79-, 50.07-, and 1.02-fold its ME, cisplatin, and doxorubicin, respectively.

\subsection{Antioxidative Activities of $9 \mathrm{MEs}$ and Their Fractions.} The antioxidative activities of 9 MEs and their fractions were presented in Table 2. The MF of C. sappan exhibited the highest DPPH radical scavenging activity with the $\mathrm{SC}_{50}$ of $21.91 \mu \mathrm{g} / \mathrm{mL}$ which was 1.09 - and 0.84 -fold $\alpha$-tocopherol $\left(\mathrm{SC}_{50}=23.80 \mu \mathrm{g} / \mathrm{mL}\right)$ and ascorbic acid $\left(\mathrm{SC}_{50}=18.30 \mu \mathrm{g} / \mathrm{mL}\right)$, respectively. HF of $S$. alata gave the highest metal chelating activity with the $\mathrm{CC}_{50}$ of $45.60 \mu \mathrm{g} / \mathrm{mL}$ which was 0.28 -fold EDTA, the standard chelating agent $\left(\mathrm{CC}_{50}=12.90 \mu \mathrm{g} / \mathrm{mL}\right)$. Interestingly, the high phenolic and flavonoid contents were related to the strong antioxidative $\mathrm{DPPH}$ radical scavenging and metal chelating activities (Table 2). ME of C. sappan showed the highest phenolic contents with the QE of $475.41 \mu \mathrm{g} / \mathrm{mg}$, whereas the MF of $R$. nasutus gave the highest flavonoid contents with the QE of $35.91 \mu \mathrm{g} / \mathrm{mg}$.

3.3. Antiproliferative and Oxidative Activities of the Semipurified Fractions from HF of $V$. denticulata. Only HF of $V$. denticulata was further semipurified by column chromatography using polarity range solvents since the active constituents that are responsible for the potent antiproliferative activity have not been much investigated. The seven semipurified fractions were evaluated for antiproliferative activity (Table 3 ). The HF2 fraction exhibited potent antiproliferative activity with the $\mathrm{IC}_{50}$ value of $6.49 \mu \mathrm{g} / \mathrm{mL}$ which was $2.97-, 4.07-$, and 0.08 fold its HF, cisplatin, and doxorubicin, respectively. The HF4 which gave the strongest metal chelating activity $\left(\mathrm{CC}_{50}=\right.$ $158.45 \mu \mathrm{g} / \mathrm{mL})$ with the highest phenolic $(\mathrm{QE}=169.99 \mu \mathrm{g} / \mathrm{mg})$ and flavonoid contents $(\mathrm{QE}=556.54 \mu \mathrm{g} / \mathrm{mg})$ was regarded as MA antiproliferative activity $\left(\mathrm{IC}_{50}=59.60 \mu \mathrm{g} / \mathrm{mL}\right)$. Phenolic and flavonoid compounds might be responsible for the potent antiproliferative activity of $V$. denticulata. The preparative HPLC of HF-2 of $V$. denticulata yielded a single compound, emodin (60.6 mg, $R_{t} 19.62 \mathrm{~min}$ ) which was characterized by the ${ }^{1} \mathrm{H}$ and ${ }^{13} \mathrm{C}$-NMR spectra comparing with the reference data $[10,11]$. The chemical structure of emodin was shown in Figure 2. The spectral data of isolated compound was as follow.

Emodin; ${ }^{1} \mathrm{H}-\mathrm{NMR}\left(400 \mathrm{MHz}, \mathrm{DMSO}-\mathrm{d}_{6}\right): \delta 2.38(\mathrm{~s}, 3 \mathrm{H})$, $6.52(\mathrm{~d}, J=1.6 \mathrm{~Hz}, 1 \mathrm{H}), 7.05(\mathrm{~s}, 1 \mathrm{H}), 7.11(\mathrm{~s}, 1 \mathrm{H}), 7.43(\mathrm{~s}$, $1 \mathrm{H}),{ }^{13} \mathrm{C}-\mathrm{NMR}\left(100 \mathrm{MHz}, \mathrm{DMSO}-\mathrm{d}_{6}\right): \delta 21.96,108.36,108.98$, $109.74,113.83,120.84,124.53,133.22,135.46,148.51,161.83$, $164.99,166.84,181.90,189.75$.

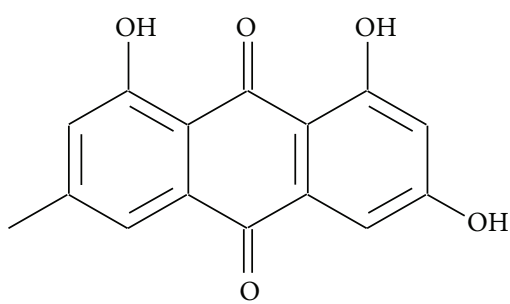

Emodin (PubChem CID: 3220)

FIgURE 2: The structure of isolated compound from the HF-2 fraction of $V$. denticulata stem.

\section{Discussion}

Twenty-three plants were found in high frequency in the anticancer recipes which were selected from the "MANOSROI III" database. Although most recipes were traditionally prepared by boiling with water, in this study these 23 plants were extracted by methanol, a high polarity range solvent under reflux. Then, the wide polarity range of constituents comparing with the water extract will be obtained. The anticancer activities of phytochemicals in some of the 23 plants have been previously reported. Saponins isolated from $A$. chinensis stem bark extract had cytotoxic activity on human colon, hepatoma, lung, and gastric cancer cell lines [12]. Brazilin (homoisoflavonoid) from the heartwood of C. sappan showed antiproliferative activity against human glioblastoma cells (U87) via apoptosis induction [13]. Thiocolchicoside (colchicinoidal compounds) from the plant G. superba exhibited anticancer activity against leukemia, myeloma, squamous cell carcinoma, breast, colon, and kidney cancer cells through inhibition of $\mathrm{NF}-\kappa \mathrm{B}$ and $\mathrm{NF}-\kappa \mathrm{B}$ regulated gene products [14]. Rhinacanthin- $\mathrm{C}$ (naphthoquinone esters) from the roots of $R$. nasutus gave antiproliferative activity against panel of 10 kinds of cancer cells (KB, Hep-2, MCF-7, HepG2, HeLa SiHa, C-32, LLC, Colon-26, and P388) together with antitumor activity in Meth-A sarcoma bearing mice [15].

As shown in Table 1 , the ME of S. collinsae exhibited the highest antiproliferative activity on HepG2 cell line. According to the NCI criteria, 1 (4.34\%) and 8 (34.78\%) out of 23 plants were considered as A and MA of antiproliferative activity, respectively, whereas other 14 plant extracts did not exhibit any activity, even though they were the composition of the anticancer recipes. These plants might have activity on other cancers, but not on HepG2 cell line or have other supporting or synergistic effects for cancer treatment, such as antitumor and anti-inflammatory activities or reduced the toxicity of other plants. It has been previously reported that C. fistula seed extracts have antitumor activity in Ehrlich ascites carcinoma [16], whereas $A$. ebracteatus showed antiinflammatory activities [17]. The medicinal plants in the recipe N040 such as C. sappan, A. chinensis, and Sida rhombifolia which showed potent antiproliferative activity on HeLa (human cervical adenocarcinoma) cell have been reported to have antiproliferative effect. The antiproliferative activity of the recipe N040 might be due to the bioactive 


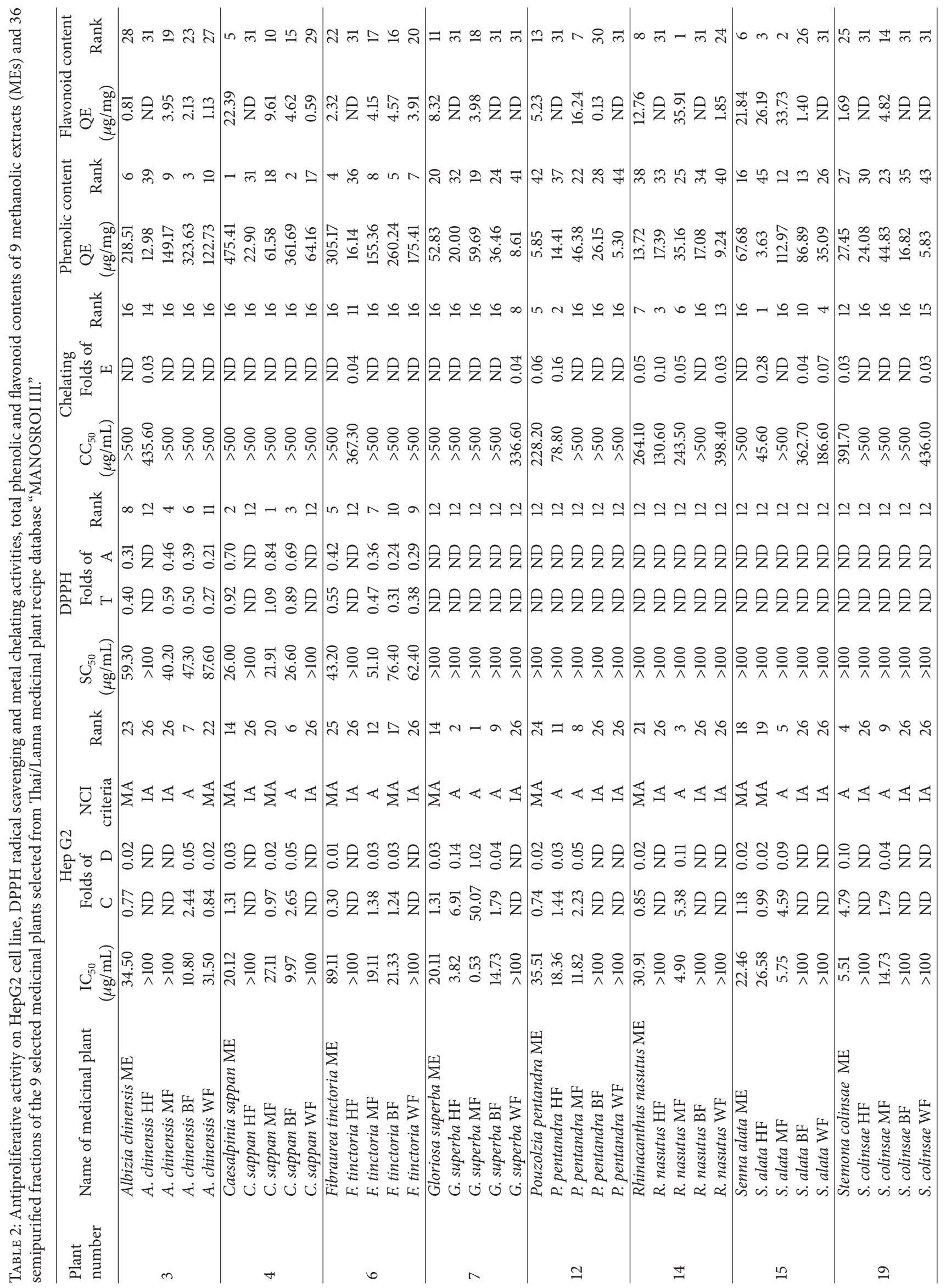




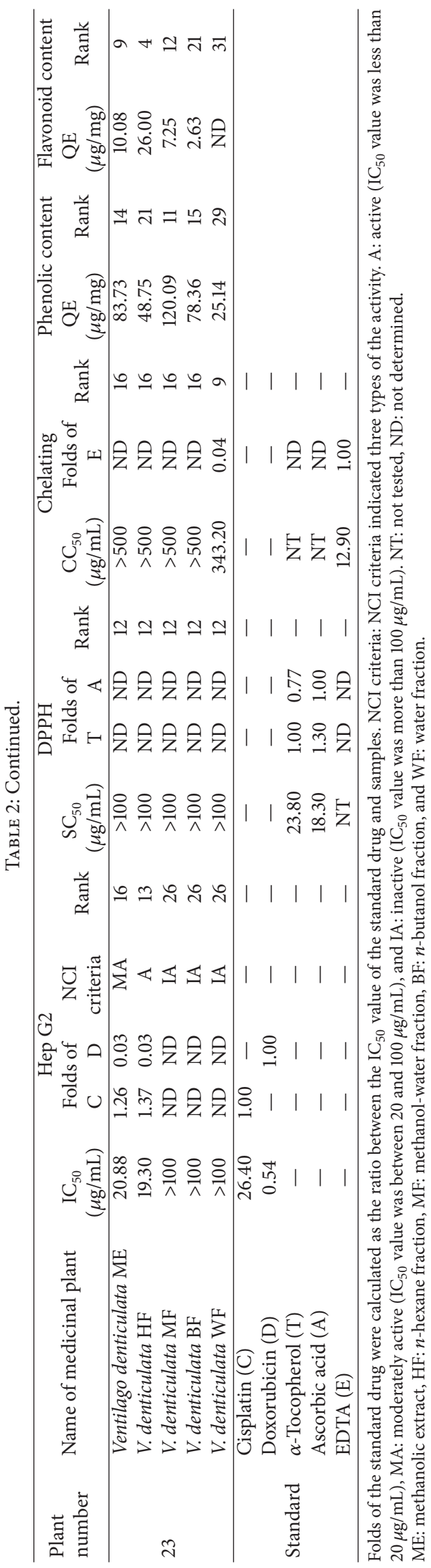




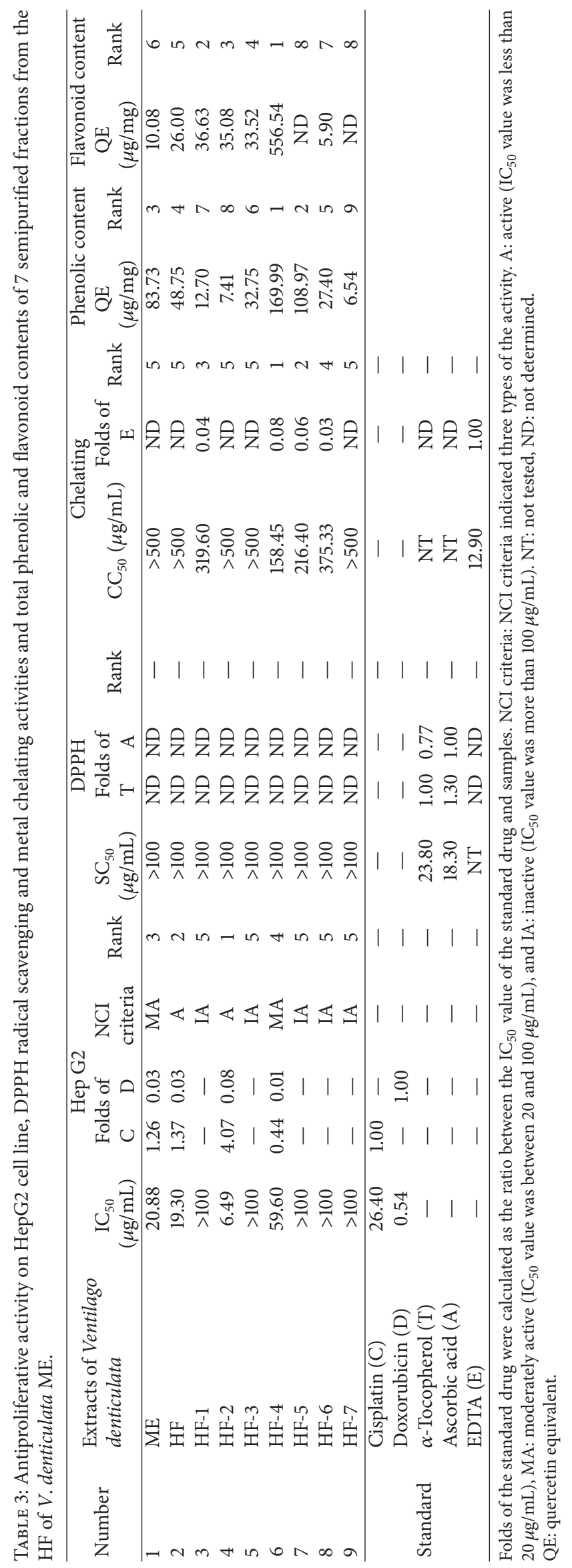


compounds from the mixed medicinal plants in the recipe [18].

After fractionation, all fractions from MEs of the 9 selected plants except $S$. collinsae showed higher antiproliferative activity than their corresponding MEs. Although the fraction from S. collinsae gave lower activity than its ME, its activity was still in the A range. This study indicated that liquid-liquid partition technique appeared to be a suitable purification method to obtain the active anticancer fraction. In Table 2, MF of G. superba indicated the highest activity. The activity might be mainly due to the colchicine of the plant in the nonpolar fractions $[14,19]$. No study on the highly polar fractions of the methanolic extract of this plant has been reported. In this study, not only has the nonpolar fraction (HF) of this plant been investigated, but the higherpolar fraction $(\mathrm{BF})$ which exhibited the high antiproliferative activities on HepG2 cell line was also described.

For antioxidative activities, MF of C. sappan exhibited the highest DPPH radical scavenging activities. In fact, the similar antioxidative and anticancer activities of C. sappan have been previously reported $[20,21]$. One of the major components of C. sappan heartwood was homoisoflavanoids [22-24]. HF of S. alata showed the highest metal chelating activity. The nonpolar constituents such as flavonoids of $S$. alata seemed to play a role for the metal chelating activity. Phenolic compounds such as flavonoids, phenolic acids, and tannins are attributed to the antioxidative effect of $S$. alata [25]. ME of C. sappan and MF of R. nasutus indicated the highest phenolic and flavonoid contents, respectively. As known, phenolic compounds such as flavonoids, phenolic acids, and tannins are considered as the major contributor to the antioxidative property of vegetables, fruits, or medicinal plants. The antioxidative activity of the phenolic compounds was attributed to its redox properties, which allowed them to act as reducing agents, hydrogen donators, singlet oxygen quenchers, and also metal chelating properties [26]. The strong DPPH radical scavenging and metal chelating activities of ME of C. sappan and MF of R. nasutus might be from the presence of phenolic compounds and flavonoids.

Twelve out of 36 fractions of the 9 selected plants were regarded as A antiproliferative activity (Table 2). The active compounds in some plants which were responsible for the potent antiproliferative activity have been reported. Colchicine from G. superba, brazilin and brazilein (homoisoflavonoids) from C. sappan, and rhinacanthin-C (naphthoquinone esters) from $R$. nasutus have been reported as active compounds responsible for the antiproliferative activity of their MEs and fractions [13-15, 27]. Besides, stemofoline (stemona alkaloids) from S. collinsae has been reported as chemosensitizer agents that increase chemosensitivity in the treatment of multidrug-resistant cancers [28]. However, the antiproliferative constituents in $V$. denticulata were not clearly identified, whereas anthraquinones have been found in this plant [29]. This study has been the first description of antiproliferative activity of $V$. denticulata on human hepatoma cell line (Hep G2). HF of $V$. denticulata which indicated improved activity comparing to its ME was further semipurified. In Table 3, HF-2 fraction exhibited the highest antiproliferative activity with $4.07-$ and 0.08 fold cisplatin and doxorubicin, respectively, whereas the HF4 fraction gave the highest metal chelating activity and contained the highest phenolic and flavonoid contents. By preparative HPLC of HF-2 fraction, emodin was isolated as the major constituent. Emodin and its derivatives have been reported as the major constituents of the root bark of V. denticulata [30]. The antiproliferative activity on HepG2 cell line of emodin with the $\mathrm{GI}_{50}$ of $13.1 \mu \mathrm{M}(3.4 \mu \mathrm{g} / \mathrm{mL})$ has been indicated [31]. Also, emodin has been shown to have ability to induce the apoptosis on HepG2 and HeLa cell lines [32-34]. Hence, emodin may be responsible for the potent antiproliferative activity on HepG2 cell line. This present study has first described the antiproliferative activity of emodin in Hep G2 cell line. However, the anticancer activity against Hep G2 cell line of emodin isolated from $V$. denticulata in animals has never been reported. Hence, the in vivo anticancer activity using Hep G2 cell xenograft nude mice model will be further investigated.

\section{Conclusion}

The antiproliferative activity on Hep G2 cell line of the 23 medicinal plants selected from the "MANOSROI III" database was investigated. Among the 23 MEs, S. collinsae root extract showed potent with the highest antiproliferative activity in HepG2 cell line at 4.79- and 0.10-fold cisplatin and doxorubicin, respectively. After liquid-liquid partition of the selected 9 MEs, MF of G. superba gave the highest antiproliferative activity at 50.07- and 1.02-fold cisplatin and doxorubicin, respectively. The 9 selected plants, except $S$. collinsae, indicated higher antiproliferative activity than their corresponding MEs. The highest DPPH free radical scavenging (1.09-fold $\alpha$-tocopherol) and metal chelating activities (0.28-fold EDTA) were observed in MF of C. sappan and HF of $S$. alata, respectively. After purification of HF of $V$. denticulata, emodin was isolated. This compound seemed to be responsible for the antiproliferative activity of $V$. denticulata. This study has confirmed not only the traditional use of the Thai/Lanna medicinal plant recipes for cancer treatments, but also the potential of plants selected from these recipes for the further development to modern anticancer drug with antioxidative activities.

\section{Disclaimer}

The authors alone are responsible for the content and writing of the paper.

\section{Conflict of Interests}

The authors report no conflict of interests.

\section{Acknowledgments}

The authors would like to thank the Agricultural Research Development Agency (Public Organization), the investment funds following the Royal Decree (ARDA) in Thailand; the 
Institute of Thai Traditional Medicine, Ministry of Public Health, Nonthaburi, Thailand; the Thailand Research Fund (TRF) under RGJ-PhD Program and the Manose Health and Beauty Research Center, Co. Ltd., in Chiang Mai, Thailand for their financial supports of this study.

\section{References}

[1] M. Kumar, X. Zhao, and X. W. Wang, "Molecular carcinogenesis of hepatocellular carcinoma and intrahepatic cholangiocarcinoma: one step closer to personalized medicine?" Celle Bioscience, vol. 1, no. 1, article 5, 2011.

[2] J. Manosroi, A. Manosroi, and U. Rungruangsri, "Translation of Lanna medicinal-plant recipes for research and development of modern pharmaceuticals and the understanding of the Lanna Thai cultures/histories," Chiang Mai University Journal, vol. 5, pp. 437-441, 2006.

[3] J. Manosroi, M. Sainakham, W. Manosroi, and A. Manosroi, "Anti-proliferative and apoptosis induction activities of extracts from Thai medicinal plant recipes selected from MANOSROI II database," Journal of Ethnopharmacology, vol. 141, no. 1, pp. 451459, 2012.

[4] P. Houghton, R. Fang, I. Techatanawat, G. Steventon, P. J. Hylands, and C. C. Lee, "The sulphorhodamine (SRB) assay and other approaches to testing plant extracts and derived compounds for activities related to reputed anticancer activity," Methods, vol. 42, no. 4, pp. 377-387, 2007.

[5] P. Skehan, R. Storeng, D. Scudiero et al., "New colorimetric cytotoxicity assay for anticancer-drug screening," Journal of the National Cancer Institute, vol. 82, no. 13, pp. 1107-1112, 1990.

[6] J. Manosroi, R. Wilairat, and A. Manosroi, "Anti-proliferative activity of extracts from Thai plants in Guttiferae and Schisandraceae families on human cancer cell lines," Pharmaceutical Biology, vol. 45, no. 3, pp. 255-258, 2007.

[7] A. Manosroi, W. Ruksiriwanich, M. Abe, H. Sakai, W. Manosroi, and J. Manosroi, "Biological activities of the rice bran extract and physical characteristics of its entrapment in niosomes by supercritical carbon dioxide fluid," The Journal of Supercritical Fluids, vol. 54, no. 2, pp. 137-144, 2010.

[8] F. Pourmorad, S. J. Hosseinimehr, and N. Shahabimajd, "Antioxidant activity, phenol and flavonoid contents of some selected Iranian medicinal plants," African Journal of Biotechnology, vol. 5, no. 11, pp. 1142-1145, 2006.

[9] E. R. Homan, "Quantitative relationships between toxic doses of antitumor chemotherapeutic agents in animals and man," Cancer Chemotherapy Reports, vol. 3, pp. 13-19, 1972.

[10] K. Danielsen, D. W. Aksnes, and G. W. Francis, "NMR study of some anthraquinones from rhubarb," Magnetic Resonance in Chemistry, vol. 30, no. 4, pp. 359-360, 1992.

[11] T. Narender, P. Sukanya, K. Sharma, and S. R. Bathula, "Apoptosis and DNA intercalating activities of novel emodin derivatives," RSC Advances, vol. 3, no. 17, pp. 6123-6131, 2013.

[12] R. Liu, S. Ma, S. Yu et al., "Cytotoxic oleanane triterpene saponins from Albizia chinensis," Journal of Natural Products, vol. 72, no. 4, pp. 632-639, 2009.

[13] D.-Y. Lee, M.-K. Lee, G.-S. Kim, H.-J. Noh, and M.-H. Lee, "Brazilin inhibits growth and induces apoptosis in human glioblastoma cells," Molecules, vol. 18, no. 2, pp. 2449-2457, 2013.

[14] S. Reuter, S. Prasad, K. Phromnoi et al., "Thiocolchicoside exhibits anticancer effects through downregulation of NF- $\kappa \mathrm{B}$ pathway and its regulated gene products linked to inflammation and cancer," Cancer Prevention Research, vol. 3, no. 11, pp. 14621472, 2010.

[15] P. Siripong, K. Kanokmedakul, S. Piyaviriyakul et al., "Antiproliferative naphthoquinone esters from Rhinacanthus nasutus Kurz. roots on various cancer cells," Journal of Traditional Medicines, vol. 23, pp. 166-172, 2006.

[16] M. Gupta, U. K. Mazumder, N. Rath, and D. K. Mukhopadhyay, "Antitumor activity of methanolic extract of Cassia fistula L. seed against Ehrlich ascites carcinoma," Journal of Ethnopharmacology, vol. 72, no. 1-2, pp. 151-156, 2000.

[17] P. Laupattarakasem, P. J. Houghton, J. R. S. Hoult, and A. Itharat, "An evaluation of the activity related to inflammation of four plants used in Thailand to treat arthritis," Journal of Ethnopharmacology, vol. 85, no. 2-3, pp. 207-215, 2003.

[18] W. Kitdamrongtham, A. Manosroi, H. Akazawa et al., "Potent anti-cervical cancer activity: synergistic effects of Thai medicinal plants in recipe N040 selected from the MANOSROI III database," Journal of Ethnopharmacology, vol. 149, no. 1, pp. 288296, 2013.

[19] C. Mahidol, S. Ruchirawat, H. Prawat, and S. Wongbundit, "Cytotoxic natural products from Thai plants: a recent study," Pharmaceutical Biology, vol. 38, pp. 6-15, 2000.

[20] S. Badami, S. Moorkoth, S. R. Rai, E. Kannan, and S. Bhojraj, "Antioxidant activity of Caesalpinia sappan heartwood", Biological and Pharmaceutical Bulletin, vol. 26, no. 11, pp. 1534-1537, 2003.

[21] J.-Y. Ueda, Y. Tezuka, A. H. Banskota et al., "Antiproliferative activity of Vietnamese medicinal plants," Biological and Pharmaceutical Bulletin, vol. 25, no. 6, pp. 753-760, 2002.

[22] V. L. Niranjan Reddy, V. Ravikanth, V. V. N. S. Jansi Lakshmi, U. Suryanarayan Murty, and Y. Venkateswarlu, "Inhibitory activity of homoisoflavonoids from Caesalpinia sappan against Beauveria bassiana," Fitoterapia, vol. 74, no. 6, pp. 600-602, 2003.

[23] X. Zhong, B. Wu, Y. J. Pan, and S. Zheng, "Brazilein inhibits survivin protein and mRNA expression and induces apoptosis in hepatocellular carcinoma HepG2 cells," Neoplasma, vol. 56, no. 5, pp. 387-392, 2009.

[24] C. T. Yen, K. Nakagawa-Goto, T. L. Hwang et al., "Antitumor agents. 271: total synthesis and evaluation of brazilein and analogs as anti-inflammatory and cytotoxic agents," Bioorganic and Medicinal Chemistry Letters, vol. 20, no. 3, pp. 1037-1039, 2010.

[25] K. Sarkar, S. Khodre, P. Patel, and M. Mandaniya, "HPLC analysis and antioxidant potential of plant extract of Cassia alata," Asian Journal of Pharmaceutical Science \& Technology, vol. 4, pp. 4-7, 2014.

[26] E. S. Abdel-Hameed, S. A. Baziad, and M. M. Shohayeb, “Total phenolic and antioxidant activity defatted fresh Taif rose, Saudi Arabia," British Journal of Pharmaceutical Research, vol. 2, no. 3, pp. 129-140, 2012.

[27] C.-H. Liang, L.-P. Chan, T.-H. Chou et al., "Brazilein from Caesalpinia sappan L. Antioxidant inhibits adipocyte differentiation and induces apoptosis through caspase-3 activity and anthelmintic activities against hymenolepis nana and anisakis simplex," Evidence-based Complementary and Alternative Medicine, vol. 2013, Article ID 864892, 14 pages, 2013.

[28] W. Chanmahasathien, C. Ampasavate, H. Greger, and P. Limtrakul, "Stemona alkaloids, from traditional Thai medicine, increase chemosensitivity via P-glycoprotein-mediated multidrug resistance," Phytomedicine, vol. 18, no. 2-3, pp. 199-204, 2011. 
[29] B. K. Rao, T. Hanumaiah, C. P. Rao, G. S. R. Rao, K. V. J. Rao, and R. H. Thomson, "Anthraquinones in Ventilago species," Phytochemistry, vol. 22, no. 11, pp. 2583-2585, 1983.

[30] M. Preeti, P. Shweta, and S. Shreyas, "In vitro anthelmintic activity of whole plant of Ventilago denticulata willd. against Pheretima posthuma," Asian Journal of Pharmaceutical and Clinical Research, vol. 5, no. 3, pp. 200-201, 2012.

[31] L. M. Zhao, L. M. Zhang, J. J. Liu et al., "Synthesis and antitumor activity of conjugates of 5-Fluorouracil and emodin," European Journal of Medicinal Chemistry, vol. 47, no. 1, pp. 255-260, 2012.

[32] D.-E. Shieh, Y.-Y. Chen, M.-H. Yen, L.-C. Chiang, and C.-C. Lin, "Emodin-induced apoptosis through p53-dependent pathway in human hepatoma cells," Life Sciences, vol. 74, no. 18, pp. 22792290, 2004.

[33] Y. Wang, H. Z. Yu, Y. Zhang, Y. Liu, X. Ge, and X. Wu, "Emodin induces apoptosis of human cervical cancer hela cells via intrinsic mitochondrial and extrinsic death receptor pathway," Cancer Cell International, vol. 13, no. 1, article 71, 2013.

[34] J.-Q. Yu, W. Bao, and J.-C. Lei, "Emodin regulates apoptotic pathway in human liver cancer cells," Phytotherapy Research, vol. 27, no. 2, pp. 251-257, 2013. 


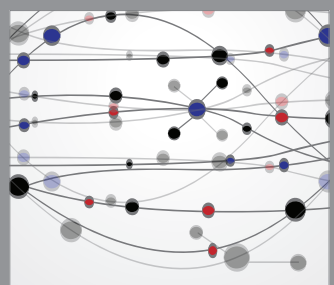

The Scientific World Journal
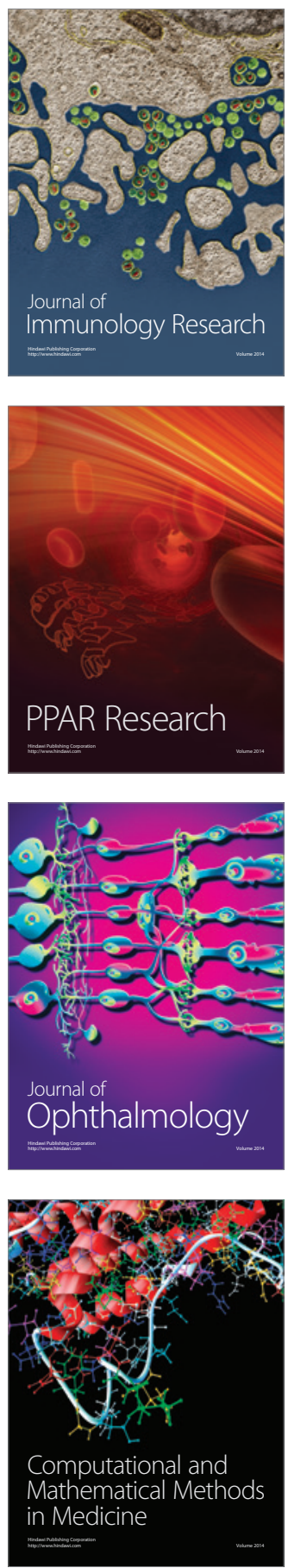

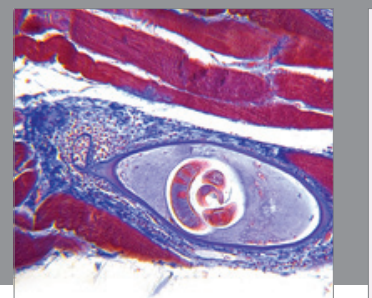

Gastroenterology

Research and Practice
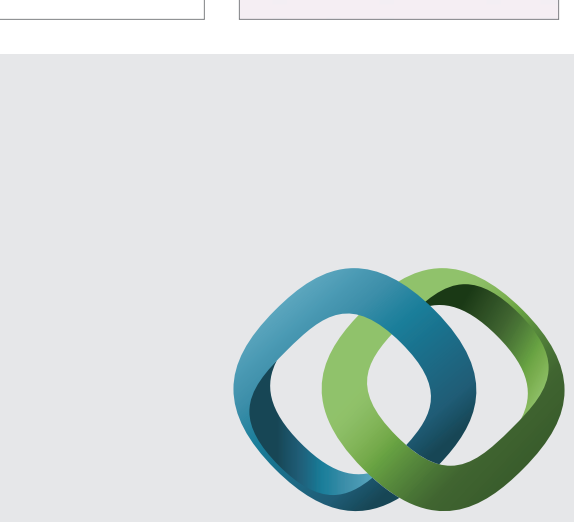

\section{Hindawi}

Submit your manuscripts at

http://www.hindawi.com
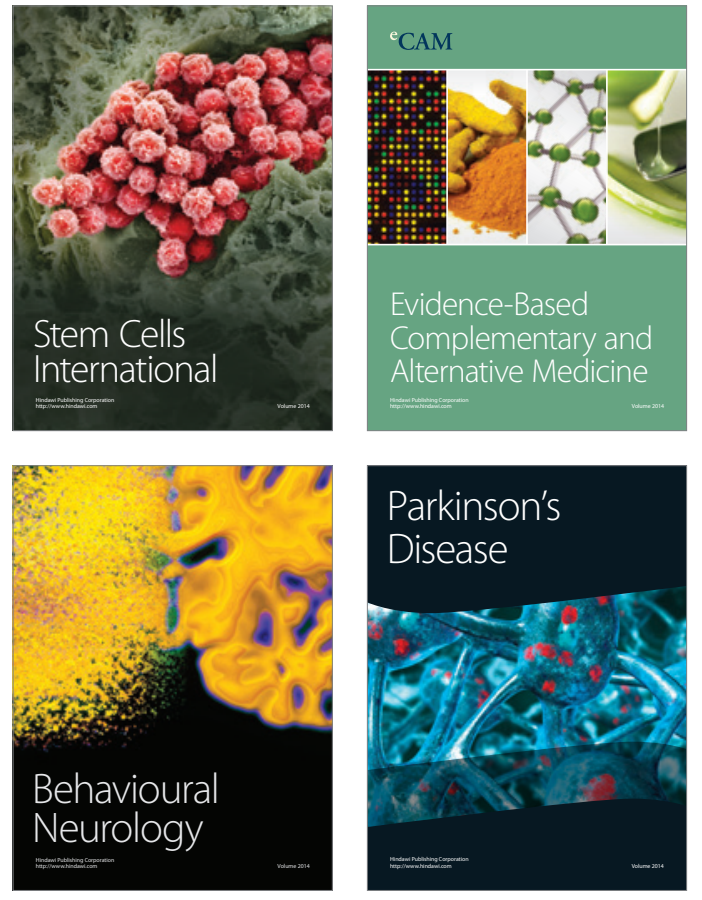
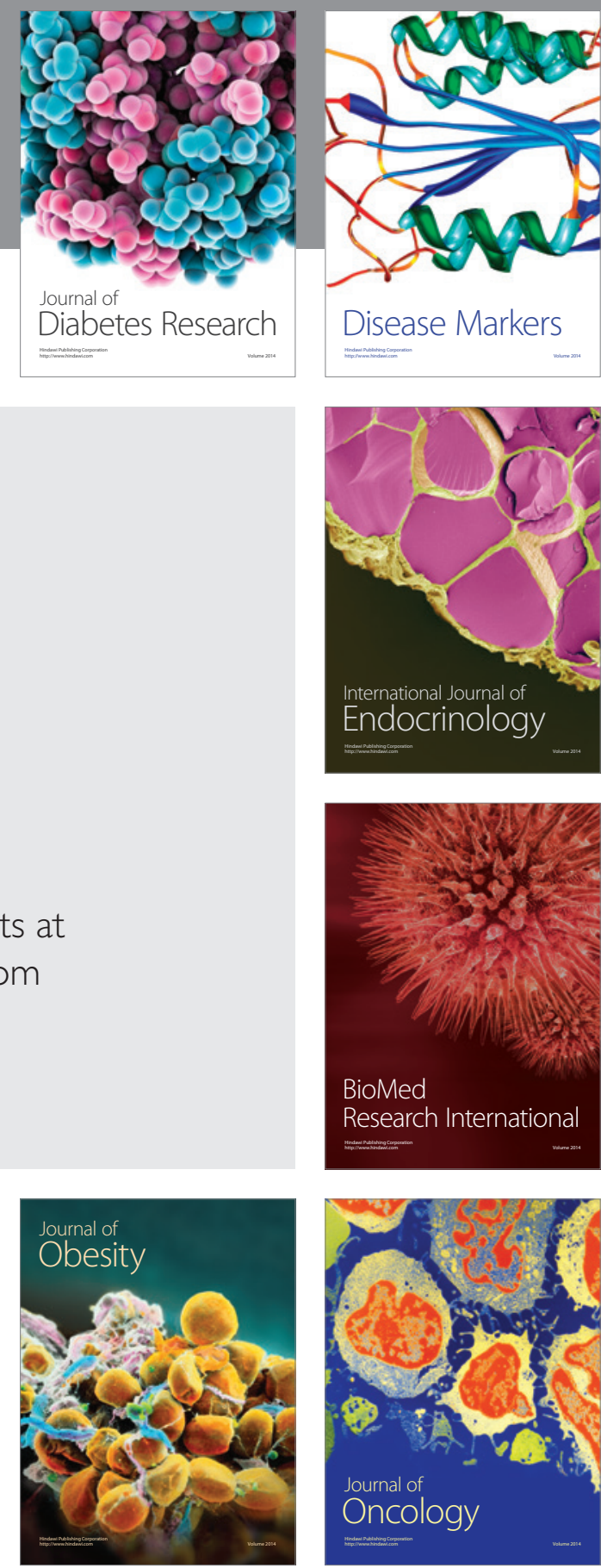

Disease Markers
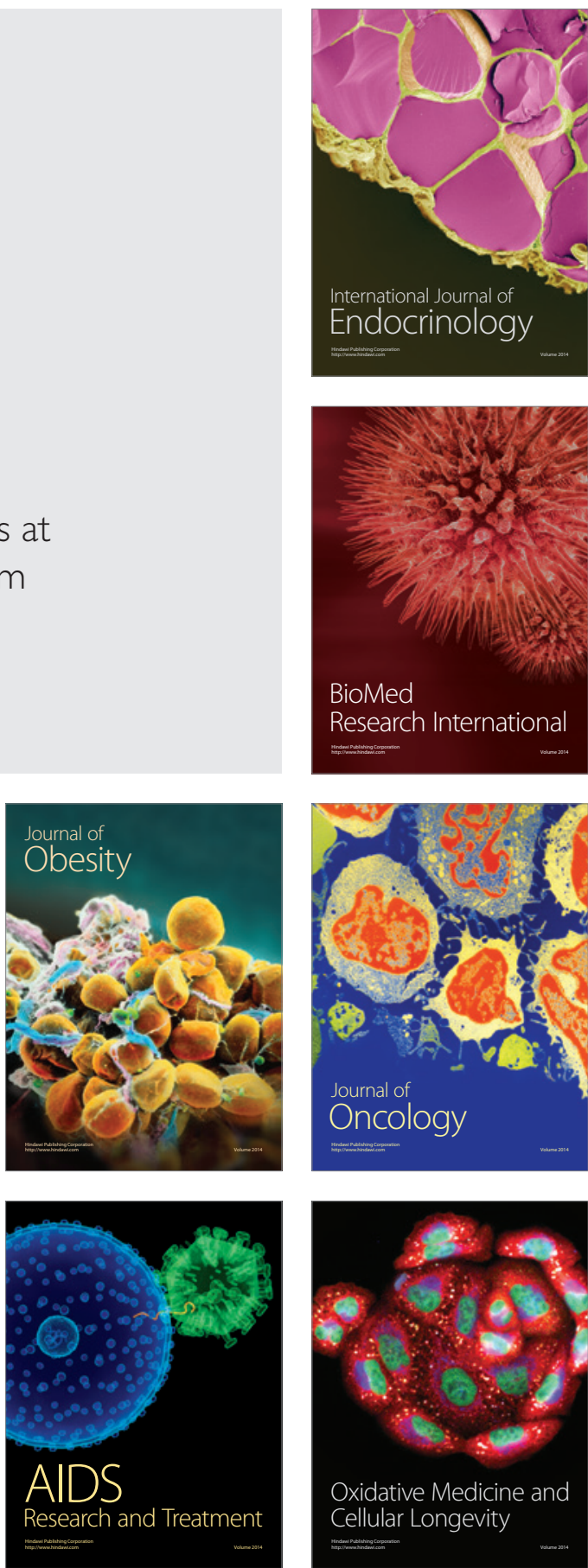